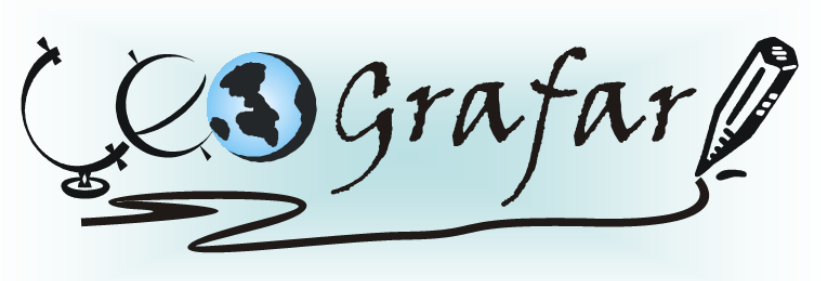

Revista Eletrônica do Programa de Pós-Graduação em Geografia - UFPR

\title{
A PAISAGEM UTILIZADA PELA ANTA (TAPIRUS TERRESTRIS) NA FLORESTA COM ARAUCÁRIA, PARANÁ, BRASIL
}

\author{
THE LANDSCAPE EMPLOYED BY TAPIR (TAPIRUS TERRESTRIS) IN \\ ARAUCARIA FOREST, PARANÁ, BRAZIL
}

\author{
Gisley Paula Vidolin \\ Pesquisadora Doutora - Bio situ Projetos e \\ Estudos Ambientais Ltda \\ Piraquara, PR, Brasil \\ e-mail:paula@biositu.com.br \\ Daniela Biondi \\ Professora Associada IV - Departamento de \\ Ciências Florestais - UFPR \\ Curitiba, PR, Brasil \\ e-mail:dbiondi@ufpr.br \\ Adilson Wandembruck \\ Pesquisador - Bio situ \\ Projetos e Estudos Ambientais Ltda \\ Piraquara, PR, Brasil \\ e-mail: adilson@biositu.com.br
}

\begin{abstract}
Resumo
Este estudo teve como objetivo conhecer a capacidade perceptual e de movimentação da anta (Tapirus terrestris) em relação à estrutura da paisagem do Corredor Ecológico Araucária, mediante a identificação das unidades paisagísticas e das rotas de deslocamento utilizadas por este tapirídeo. A pesquisa foi conduzida em 14 propriedades localizadas em um recorte espacial de $659 \mathrm{~km} 2$, entre as coordenadas geográficas $26^{\circ} 26^{\prime} 35^{\prime \prime}$ de latitude S e $51^{\circ} 46^{\prime} 10^{\prime \prime}$ de longitude W e $26^{\circ} 12^{\prime} 19^{\prime \prime}$ de latitude $S$ e $51^{\circ} 24^{\prime} 45^{\prime \prime}$ de longitude W. O método de amostragem utilizado consistiu no mapeamento dos pontos de ocorrência da anta, tendo como base, entrevistas com moradores locais e a busca por indícios como pegadas,
\end{abstract}


carreiros e outros sinais que atestassem a sua presença nas áreas amostrais. As áreas foram visitadas mensalmente ao longo do período de 18 meses. Foram identificadas algumas rotas de deslocamento estáveis $(n=5)$, que são sempre utilizadas pela espécie para trânsito entre as propriedades. Estas acompanham cursos de água naturais e estão associadas às áreas de várzeas. Foi observada, ainda, uma rotatividade na utilização das áreas pela espécie, o que possivelmente esteja relacionado com a disponibilidade local de recursos alimentares. Como conclusão, foi possível inferir que a anta possui ampla capacidade perceptual, e é capaz de perceber habitats ou recursos alimentares preferenciais à distância.

Palavras-Chave: corredor ecológico, Floresta com Araucária, anta.

\section{Abstract}

This study aimed to understand the perceptual ability and handling of the tapir (Tapirus terrestris) in relation to landscape structure of the Ecological Corridor Araucaria, by identifying the landscape units and routes of travel used by this tapirídeo. Therefore, the research was conducted on 14 farms in a spatial area of $659 \mathrm{~km} 2$, located between the geographic coordinates $26^{\circ} 26^{\prime} 35^{\prime \prime}$ latitude $S$ and $51^{\circ} 46^{\prime} 10^{\prime \prime} \mathrm{W}$ longitude and $26^{\circ} 12^{\prime} 19^{\prime \prime}$ latitude $S$ and $51^{\circ} 24^{\prime} 45^{\prime \prime} \mathrm{W}$ longitude. The sampling method consisted of mapping the points of occurrence of the tapir, based on interviews with local residents and searching for clues such as footprints, pathways and other signs that indicated their presence in the sample areas. The areas were visited monthly throughout the period of 18 months. We identified some routes scroll stable $(n=5)$, which are always used by the species for transit between the properties. These come with natural waterways and are associated with low land areas. We observed also a turnover in the use of the areas by the species, which may be related to the local availability of food resources. In conclusion, it was possible to infer that the tapir has extensive perceptual capacity, and is capable of perceiving habitats or food resources preferred distance.

Keywords: ecological corridor, Araucaria Forest, tapir.

\section{Introdução}

De acordo com May (1986) os animais percebem o seu ambiente físico como um mosaico de manchas, nas quais se distribuem de uma forma não uniforme. Estas manchas podem ser usadas para diferentes finalidades (reprodução versus alimentação) ou segundo diferentes frequências de utilização (WITH et al., 1997).

Dependendo da espécie animal, nomeadamente do seu tamanho corporal, capacidade de deslocamento e tamanho de área de vida, a paisagem utilizada e 
percebida em torno da presença e distribuição de várias manchas, que foram classificadas por Danielson (1992) e Dunning (1992) como: manchas preferidas, onde, em média, a reprodução excede a mortalidade (source habitat); manchas secundárias, onde alguma reprodução ocorre, mas, em média, não é suficiente para igualar a mortalidade (sink habitat) e; manchas não exploráveis ou de transição, que compreendem a matriz de todos os habitats que nunca são explorados pela espécie e onde os habitats utilizáveis estão incluídos (unusable habitat ou transient habitat) (GOMES, 1998). Dependendo da maior ou menor ligação da espécie a um habitat específico, a sua distribuição vai depender não só da existência das manchas preferidas, mas também da sua diluição no meio das manchas secundárias ou na matriz não utilizável (GOMES, 1998). Corroborando Campos (2004) cita que o tamanho da paisagem varia dependendo em que consiste o mosaico de habitat ou recursos de manchas significativas para a espécie.

A percepção da paisagem pelas espécies também pode ser variável dependendo da estação do ano, onde o animal pode migrar ou deslocar-se a locais que se adéquem as suas necessidades básicas num determinado período de tempo. Com efeito, uma espécie provavelmente responde não apenas à presença ou ausência de determinados recursos, mas sim a um gradiente qualitativo destes. A sua percepção da estrutura paisagística vai depender também das diferentes escalas espaciais às quais a espécie interage com a distribuição desses recursos, devido a diferenças na mobilidade ou no tipo de recursos utilizados (WITH et al., 1997).

Sendo assim, o conceito de escalas múltiplas dentro de um mesmo ecossistema ou em um contexto de paisagem, deve ser considerado em estudos com fauna (MARENZI, 2004). Metzger (2001) conceitua a escala de percepção das espécies, como aquela que se refere à escala espacial e temporal na qual a espécie percebe ou interage com a paisagem. Para este autor a escala de percepção da paisagem pelas espécies está relacionada à extensão do seu território, à sua capacidade de deslocamento e de suas exigências de habitats específicos. Ainda de acordo com este autor, espécies com pequena capacidade de deslocamento ou dispersão percebem a paisagem em um contexto mais local, enquanto que espécies que possuem maior capacidade de deslocamento percebem a paisagem em uma 
escala mais ampla; ou ainda espécies com habitats muito especializados percebem a paisagem com um maior grau de detalhamento em relação às demais espécies generalistas.

IMS (2004) afirma que o movimento das espécies pela paisagem se dá em relação de sua funcionalidade biológica e de sua estrutura espacial, e propõe tipos de movimentos correlacionados com estes aspectos, tais como: (a) escala espacial de manchas de recurso os movimentos da espécie estariam relacionados à seleção de alimentos; (b) na escala espacial de manchas de habitats os movimentos estariam relacionados à procura por áreas de alimentos e vigilância do território; (c) na escala espacial do mosaico paisagístico os movimentos estariam relacionados à dispersão das espécies; e (d) e em uma escala espacial regional o movimento dos animais estaria relacionado à migração. Nesse contexto, Southwood (1977) cita que o habitat ocupado pelas espécies é dinâmico e que possui certa plasticidade, ou seja, muda nas escalas temporal e espacial conforme a necessidade das espécies.

Outro aspecto importante relacionado à utilização dos habitats refere-se ao sucesso de seu uso pelas espécies, o que depende da relação entre a capacidade de deslocamento das espécies (escala de movimentação) e o espaçamento dos habitats (escala de fragmentação) (KIMBERLY e KING, 1999). Essa capacidade de perceber um habitat à distância é definida por Forero-Medina e Vieira (2007) como capacidade perceptual (perceptual range), que é a distância desde a qual um elemento da paisagem pode ser percebido ou detectado por um determinado animal. Segundo esses autores, um animal com uma estreita capacidade perceptual terá um risco de mortalidade relativamente alto, pois gastará mais tempo procurando um habitat favorável que um animal com uma distância de capacidade perceptual ampla. Da mesma forma, a sensibilidade de uma espécie à fragmentação será em função da sua capacidade perceptual (ZOLLNER, 2000).

A anta é o maior mamífero terrestre ocorrente no Brasil e seus aspectos biológicos são inconfundíveis, tanto por seu tamanho quanto por sua forma corporal. São animais corpulentos, atingindo em média o comprimento total de 2,00 $\mathrm{m}$ e chegando a pesar cerca de 227 a $300 \mathrm{~kg}$ quando adultos (EMMONS, 1990). Encontra-se listada pela União Internacional para a Conservação da Natureza (IUCN - International Union for the Conservation of Nature) como "Vulnerável à Extinção" 
nas categorias $A 1 c d+2 c+3 c$ (IUCN, 2007). No Brasil, apesar de não constar nas listas do IBAMA, é citada em diferentes status de ameaça em listas estaduais (Minas Gerais e Rio Grande do Sul consta como "criticamente em perigo", e nos estados de São Paulo, Rio de Janeiro e Paraná como "em perigo" (MIKICH e BÉRNILS, 2004). Segundo IUCN (2008) no Brasil existem populações consideráveis da espécie na Amazônia e no Mato Grosso do Sul, mas que devido a diferentes tipos de pressões antrópicas, estão em declínio (PADILLA e DOWLER, 1994). No Paraná, ocorria em praticamente todos os biomas, no entanto, atualmente vem desaparecendo juntamente com a destruição das florestas (MIKICH e BÉRNILS, 2004).

A anta utiliza tanto habitats de montanha como de baixada, sempre nos trópicos, sendo caracteristicamente associada a florestas tropicais ou florestas montanas tropicais. Pode ocupar, ainda, savanas ou florestas secas e decíduas, mas geralmente na proximidade de florestas ribeirinhas (EISENBERG, 1997). Segundo Richard e Juliá (2000), as antas são altamente dependentes da água ou de ambientes úmidos para realizar várias funções vitais de seu ciclo de vida.

Segundo Fragoso (1994) a caça é o principal fator do desaparecimento das antas em alguns locais onde sua ocorrência era comum. Por ser uma espécie com pequeno espectro de tolerância a variações no habitat é considerada indicadora ambiental, estando sua presença em um determinado ambiente correlacionada ao seu bom grau de conservação (BODMER e BROOKS, 1997; MONTENEGRO, 1997), sobretudo de ambientes úmidos.

Nesse sentido, a idéia central dessa análise foi a de obter informações referentes aos tipos de movimentos da anta em relação à funcionalidade biológica e estrutura espacial da paisagem. Para tanto foram obtidas informações referentes à: (a) disponibilidade dos habitats; (b) tamanho e formato das manchas desses habitats; (c) sensibilidade da espécie à fragmentação em função da disponibilidade de habitats preferenciais; e (d) existência de elementos conexão que facilitam o deslocamento da espécie entre manchas de habitats. 


\section{Material e métodos}

\section{Área de Estudo}

Este estudo foi conduzido em 14 propriedades situadas na porção sul do Corredor Ecológico Araucária, criado pelo Governo do Estado do Paraná, mediante o Programa Paraná Biodiversidade, em uma parceria com o Governo de Estado e o Banco Mundial (GEF) (Figura 1).

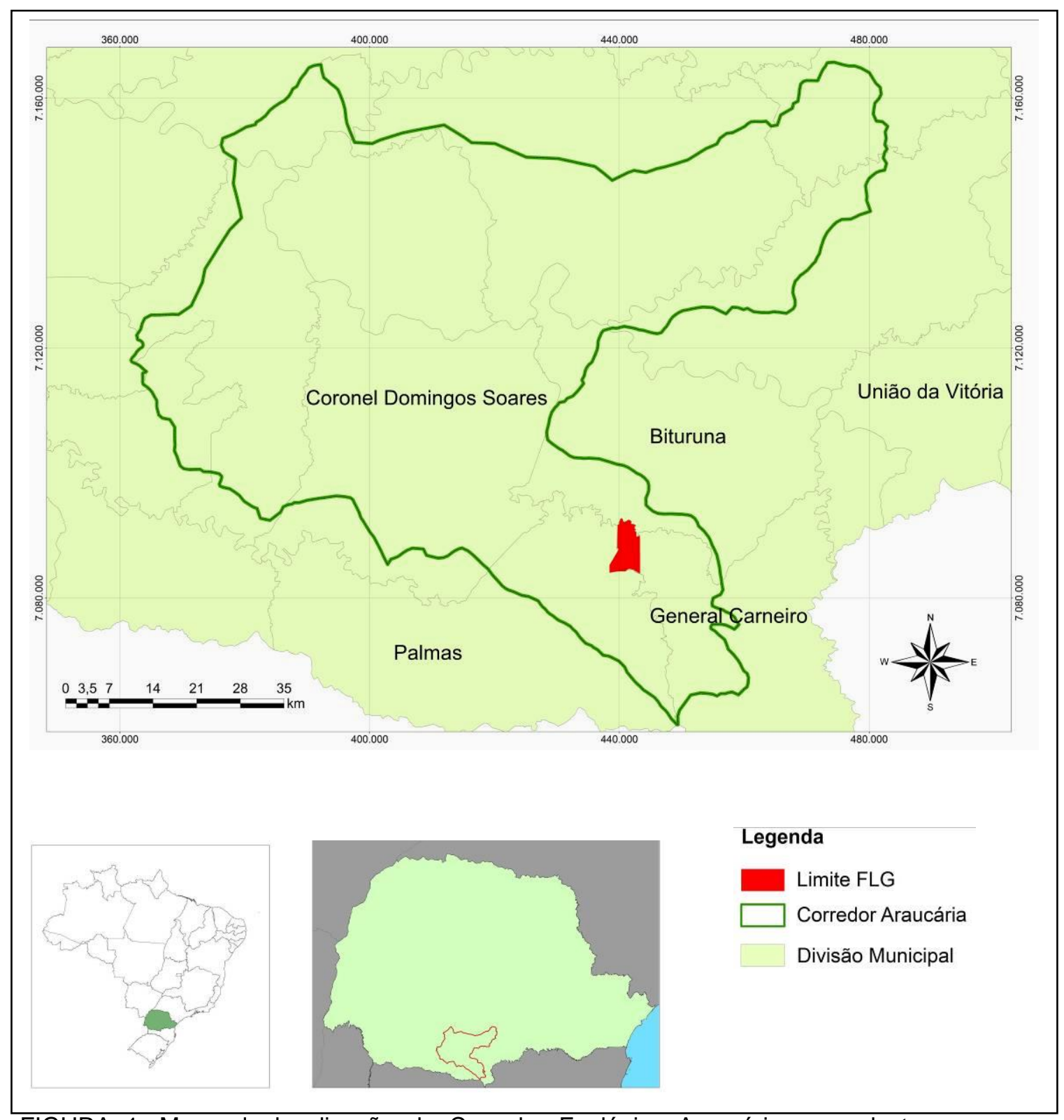

FIGURA 1. Mapa de localização do Corredor Ecológico Araucária, com destaque para a Fazenda Lageado Grande (FLG), Paraná, Brasil. Base de dados cartográficos: Paraná (2006).

O Corredor Ecológico Araucária está localizado no Terceiro Planalto do Estado, entre as coordenadas geográficas $50^{\circ} 55^{\prime} 39^{\prime \prime}$ e $52^{\circ} 23^{\prime} 37^{\prime \prime}$ de longitude W, e 
entre as latitudes Sul 25034'35" e $26^{\circ} 43^{\prime} 28^{\prime \prime}$ (Figura 1). Abrange 11 municípios da região Centro-Sul, totalizando uma área de $12.472 \mathrm{~km}^{2}$. Faz divisas a leste com a Serra da Esperança, ao sul com o Estado de Santa Catarina, e a oeste e norte com outros municípios paranaenses. Seu eixo principal de conexões é o Rio Iguaçu e seus tributários. Além da Floresta Ombrófila Mista, há na região do Corredor a influência da Floresta Estacional Semidecidual pelo vale do rio Iguaçu, bem como de campos limpos nas regiões mais elevadas do Terceiro Planalto. Abriga diversas espécies da flora e da fauna ameaçadas de extinção (PARANÁ, 2006).

As propriedades consideradas para este estudo estão inseridas em um recorte espacial de $659 \mathrm{~km}^{2}$, situado entre as coordenadas geográficas $26^{\circ} 26^{\prime} 35^{\prime \prime}$ de latitude $S$ e $51^{\circ} 46^{\prime} 10^{\prime \prime}$ de longitude W e $26^{\circ} 12^{\prime} 19^{\prime \prime}$ de latitude $S$ e $51^{\circ} 24^{\prime} 45^{\prime \prime}$ de longitude W, sendo elas (Figura 2):

(a) Fazenda Lageado Grande (FLG), com 3.136,32 ha, de propriedade das Indústrias Pedro N. Pizzatto, situada entre os municípios de Palmas, General Carneiro e Bituruna. O Rio Iratim, que apresenta variação de largura entre 10 e $50 \mathrm{~m}$ e estende-se por cerca de $20 \mathrm{~km}$ na propriedade, é o principal rio da área. A porção norte da propriedade, caracterizada integralmente por floresta com predomínio de araucária e manchas de várzeas. As porções central e sul da referida área são constituídas por um mosaico paisagístico de reflorestamento com pinus (Pinus spp.), floresta com predomínio de folhosas, floresta com predomínio de pinheiro e várzeas. São nessas duas porções que se concentra a grande maioria das atividades de exploração florestal.

(b) Fazenda Lageado Grande (cerca de 4.800 ha) e Fazendas Santa Cruz (cerca de $2.800 \mathrm{ha}$ ), ambas de propriedade da Remasa Reflorestadora S.A., localizadas em Bituruna e Palmas, respectivamente. São áreas constituídas por remanescentes de florestas nativas em diferentes estágios sucessionais que se alternam com extensas áreas de plantios de pinus. Os principais rios que cortam as áreas são o Lageado Grande e o São Lourenço, respectivamente.

(c) Fazenda Etiene (cerca de 1.500 ha) de propriedade do Sr. Ernesto Schuega, que é contígua à Fazenda Faxinal dos Santos (aproximadamente 2.500 ha) de propriedade da empresa Miguel Forte, ambas situadas em General Carneiro. Estas áreas possuem um mosaico paisagístico constituído predominantemente por 
áreas de floresta com predomínio de araucária em estágio avançado e médio de regeneração, intercaladas com faixas de floresta com predomínio de folhosas e várzeas. Os ambientes são semelhantes aos da FLG. O principal rio que corta a área é o Lageado Grande.

(d) Fazenda Santa Gema Geyer (aproximadamente 7.500 ha) situada entre os municípios de General Carneiro e Palmas, de propriedade das empresas Oscar Geyer S.A. Esta fazenda é contígua a FLG, e assim como esta área, possui um mosaico paisagístico constituído predominantemente por grandes manchas de florestas com predomínio de araucária intercalado com áreas de floresta com predomínio de folhosas, várzeas e reflorestamentos com pinus. O principal rio que corta a área é o Iratim.

(e) Fazenda São Lourenço, situada em Palmas, de propriedade do Sr. Adelar Laurides Anzileiro. Possui um mosaico paisagístico constituído predominantemente por áreas agricultáveis e por reflorestamento de pinus, as quais são intercaladas com manchas de vegetação nativa, incluindo floresta com predomínio de folhosas e várzeas.

(f) Fazenda Santana (cerca de 2.300 ha), Fazenda Santa Bárbara (cerca de 1.700 ha) e Fazenda Santa Lúcia (cerca de 600 ha) áreas contíguas situadas nos municípios de Palmas e Coronel Domingos Soares, de propriedade da empresa Madepar S.A. Possuem um mosaico paisagístico constituído predominantemente por florestas com predomínio de folhosas, intercalas com manchas de vegetação secundária nas fases inicial e intermediária da sucessão vegetal. Apresentam pequenas manchas de floresta com predomínio de pinheiro e poucas manchas de várzeas.

(g) Fazenda Palmital de propriedade das empresas Guararapes/ Sudati S.A., situadas nos municípios de General Carneiro e Palmas. São áreas constituídas por remanescentes de florestas nativas em diferentes estágios sucessionais que se alternam com extensas áreas de plantios de pinus.

(h) Faxinal dos Santos e os Assentamentos rurais Margens do Iratim, Paraíso do Sul e São Lourenço, caracterizados por remanescentes de florestas nativas em diferentes estágios sucessionais que se alternam com pequenas 
pastagens, agricultura de subsistência, áreas abandonadas e, em menor grau, por médias propriedades com agricultura mecanizada.

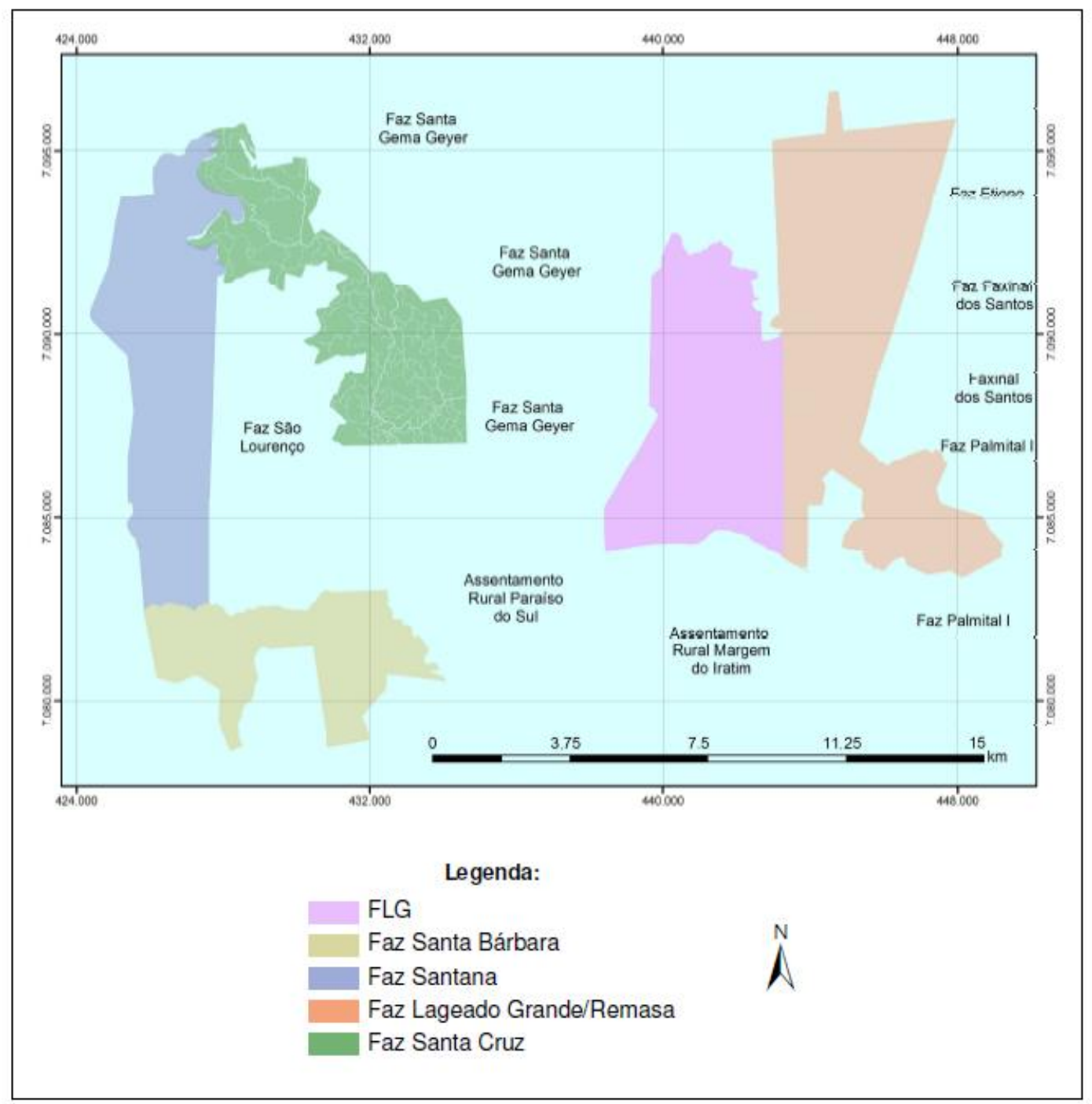

FIGURA 2. Mapa de localização das propriedades na macro-escala. Base de dados cartográficos: Paraná (2006).

\section{Procedimentos Metodológicos}

A definição da escala de percepção da paisagem da anta foi baseada nos índices de seletividade de habitats obtidos para a espécie por Vidolin (2008) e Vidolin et al. (2009), bem como nos seus requisitos ecológicos relacionados à extensão de sua área de vida, que fazem com que as espécies percebam a paisagem em um contexto mais amplo. 
A definição da extensão de área analisada na paisagem foi baseada no mapeamento dos pontos de ocorrência da anta nas propriedades estudadas. As informações iniciais sobre a ocorrência deste tapirídeo basearam-se em entrevistas com moradores locais que relataram seu conhecimento sobre a distribuição da espécie, bem como os trajetos frequentemente utilizados pela espécie para deslocamento entre propriedades. Posteriormente, foram realizadas incursões às áreas indicadas nas entrevistas visando confirmar as informações. A constatação da ocorrência da espécie nessas áreas deu-se pelo registro de sinais diagnósticos da presença dos animais como pegadas, carreiros, material escatológico, vocalizações e visualizações.

Estas áreas foram visitadas mensalmente ao longo do período de 18 meses (de janeiro de 2007 a julho de 2008) e todos os pontos onde foram encontrados sinais da anta foram marcados em GPS (UTM). Os registros confirmados foram plotados em um mapa de uso do solo da região (base de dados Paraná (2006), e os pontos extremos foram unidos, resultando em um polígono de área de uso dos animais, a qual teve sua área calculada no programa ArcMap versão 9.2. Da mesma forma, foram identificadas as rotas de dispersão (sentidos e distâncias) utilizadas pelos animais para trânsito entre as propriedades.

Inferências sobre a percepção da paisagem pela espécie foram baseadas na análise da estrutura paisagística do recorte espacial realizado sobre o polígono de área de uso da espécie, considerando-se os seus tipos de movimentos em relação à funcionalidade biológica e estrutura espacial da paisagem, conforme preconizado por IMS (2004). Também foram considerados os Limiares de Fragmentação de Andrén (1994) e de Percolação de Stauffer (1985), ambos citados por Metzger (1999), além de informações sobre aspectos ecológicos da espécie obtidas por estudos realizados na região, sobretudo nos trabalhos de Vidolin (2008) e Vidolin et al. (2009).

O "Limiar de Fragmentação de Andrén" sugere que a sensibilidade das espécies à fragmentação de habitats varia em função da proporção de área ocupada pelo habitat na paisagem. Quando a proporção de habitat na paisagem é superior a 0,30 ou $30 \%$, o tamanho da população varia particularmente em função da redução da área do habitat; e quando esta proporção é inferior a 0,30 , os fragmentos de 
habitats se dispõem de forma mais dispersa e isolada dentro de uma ampla matriz, e as espécies passam a ser particularmente sensíveis à disposição espacial dos fragmentos de habitat. Neste caso foram utilizados os valores de percentagem de ocupação de fragmentos de mesma classe na paisagem dos habitats e de proporção de elementos de conexão para avaliar o tipo de interferência que exercem sobre os animais (METZGER, 1999).

O "Limiar de Percolação de Stauffer" sugere a existência de uma probabilidade crítica (que corresponde à proporção, em área, da paisagem ocupada pelo habitat numa paisagem bimodal, formada unicamente por habitat e não-habitat) $p_{c}=0,5928$ ou $59,28 \%$ (limiar da percolação), que é o valor (constante) pelo qual a paisagem passa bruscamente de um estágio conectado (onde há percolação) para um estágio desconectado (onde não há mais percolação). Quando a proporção de habitat na paisagem $(p)$ está próxima do limiar de percolação $\left(p_{c}\right)$, ocorrem mudanças bruscas nas características dos fragmentos, em particular no número, na distribuição de áreas, nas dimensões fractais e no comprimento de bordas (METZGER, 1999). Para essa análise, o mapa de uso e cobertura do solo dos polígonos de área de uso da espécie foi reclassificado, de maneira a se obter somente duas categorias: habitat (remanescentes de vegetação nativa) e nãohabitat (ambientes gerados a partir da ação antrópica).

\section{Resultados e discussão}

Vidolin (2008) estimou o tamanho de área de uso total para anta em 4.314 ha ou $43 \mathrm{~km}^{2}$. A área de uso central foi estimada em 3.530 ha $\left(35 \mathrm{~km}^{2}\right)$, sendo que deste total a FLG representa $67 \%$ (2.351 ha). O índice de abundância relativa da anta obtido para o polígono de área de uso total foi em uma média de quatro indivíduos, valor bastante baixo. Noss et al. (2003) no Parque Nacional Kaa-lya del Gran Chaco (Bolívia), também obteve uma baixa densidade relativa para a anta, tendo estimado cinco indivíduos para uma área de $81 \mathrm{~km}^{2}$; e em 11 indivíduos para uma área de $84 \mathrm{~km}^{2}$. Seus habitats-chaves são constituídos por várzeas (a espécie seleciona este ambiente 14 vezes mais que sua disponibilidade na paisagem) e 
áreas de vegetação ciliar (selecionadas pela espécie três vezes mais que sua disponibilidade na paisagem) (VIDOLIN et al., 2009).

Foram identificadas, mediante este trabalho, que a anta possui algumas rotas de deslocamento estáveis, que são sempre utilizadas para trânsito entre FLG e as Fazendas Lageado Grande/ Remasa e a Santa Gema Geyer, tendo sido possível identificar cinco delas, conforme demonstrado na Figura 3. Todas estas rotas acompanham cursos de água naturais e estão associadas às áreas de várzeas.

Na paisagem estudada, a anta comportar-se como uma espécie sensível à heterogeneidade local (fine grained species sensu ) (FORMAN E GODRON, 1986). Ou seja, há uma rotatividade na utilização das áreas pela espécie, o que possivelmente esteja relacionado com a disponibilidade local de recursos alimentares. Na estação seca a partir do mês de maio até agosto, por exemplo, há produção de pinhão (Araucaria angustifolia). A partir do término do mês de agosto inicia-se uma fase de déficit de alimento, uma vez que frutos zoocóricos maduros passam a estar disponíveis em maior diversidade apenas a partir de novembro/ dezembro (LIESBSCH e MIKICH, 2009; LIESBSCH et al., 2009).

As rotas de deslocamento "A", "B" e "C" são utilizadas pela anta para deslocamento entre a FLG e a Fazenda Lageado Grande/ Remasa e possuem 3,2 $\mathrm{km}, 3,9 \mathrm{~km}$ e 1,3 km de comprimento, respectivamente. As rotas de deslocamento "D" e "E" são utilizadas pela espécie para deslocamento entre a FLG e a Fazenda Santa Gema Geyer, e possuem 1,6 km e 530 metros, respectivamente. Estas distâncias percorridas pela anta nesses corredores estão bem próximas daquelas obtidas por Tobler (2006) e Morais et al. (2003).

Alguns trechos das rotas de deslocamento utilizadas pelos animais passam por áreas de reflorestamento, sobretudo os da Fazenda Lageado Grande/ Remasa. Neste caso, o manejo adequado do pinus e a manutenção de manchas de ambientes naturais, em especial os ciliares, não afetam a utilização dessas áreas de plantio pela anta, quando comparado com outros tipos de uso do solo, como agricultura e pecuária (desenvolvidas no Faxinal e nos Assentamentos Rurais), onde a espécie foi pouco observada. Na Fazenda da Remasa os deslocamentos entre propriedades ocorreram, preferencialmente, em talhões mais antigos, alguns já com subosque e próximos às fontes de água. No entanto, houve alguns eventos em que 
os animais foram registrados mesmo quando havia operações de corte raso, desbaste e plantio de pinus. $O$ fato é que a melhoria das características ambientais dessas áreas com a adoção de ações simples de manejo, como a conservação de fragmentos de vegetação nativa; enriquecimento e recuperação destas áreas mediante o plantio de espécies nativas; e mesmo o plantio realizado em blocos entremeados por corredores de vegetação nativa, pode contribuir para a manutenção e continuidade do uso desses ambientes pelas espécies. Também a postura adotada pela empresa em relação à proibição da caça em suas Fazendas contribui para que os animais utilizem essas áreas sem estarem sujeitos a esse tipo de pressão. O mesmo não ocorre nas áreas do Faxinal e Assentamentos Rurais, onde as espécies sofrem frequente e intensa pressão de caça, especialmente se utilizar ou cruzar áreas de agricultura. 


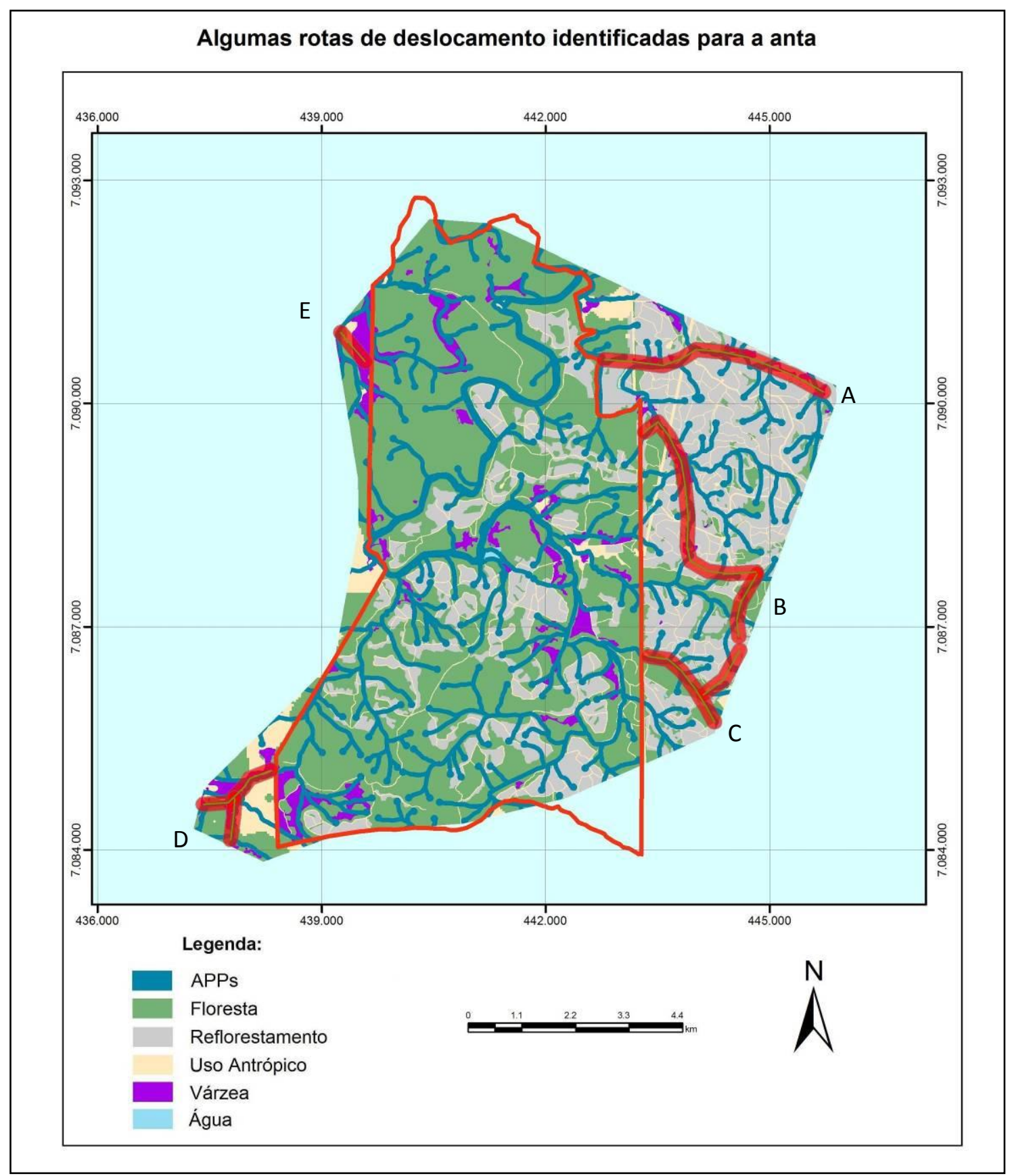

FIGURA 3. Rotas de deslocamento da anta utilizadas para trânsito entre a FLG e as demais fazendas do entorno.

Em relação aos habitats-chaves da espécie identificados por Vidolin et al. (2009) como as várzeas e áreas de vegetação ciliar, de acordo com as análises da estrutura da paisagem e do Limiar de Andrén (1994), indicam que a a anta é mais 
influenciada pela disposição espacial de seus habitats-chaves do que pelo tamanho de suas áreas ocupadas no polígono, já que as várzeas $(6,18 \%)$ ocupam proporções inferiores ao limiar considerado de $30 \%$. Quanto ao segundo tipo de habitat mais selecionado pela espécie, as áreas de vegetação ciliar representam $23,09 \%$ (CON), ou seja, podem ser considerados próximos ao limiar de Andrén (Figura 4).

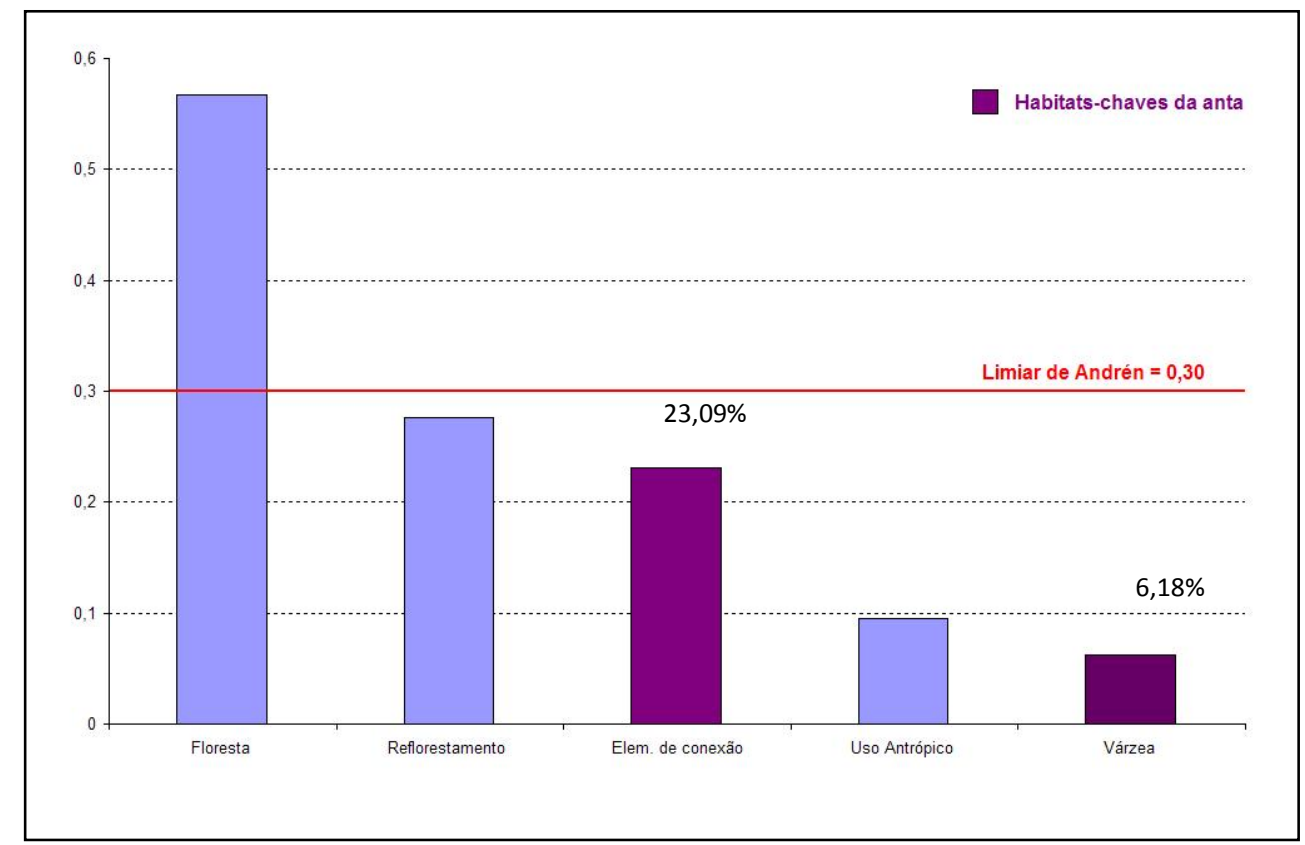

FIGURA 4. Proporções de ocupação dos habitats (Pland) e dos elementos de conexão (Con) na área de uso total da anta, comparados com o "Limiar da fragmentação de Andrén".

Avaliando-se o limiar de percolação de Stauffer (1985) pode-se afirmar que na paisagem inserida no polígono de área de uso total da anta há percolação, sendo que as proporções de habitat (remanescentes de vegetação nativa) e não-habitat (ambientes gerados a partir da ação antrópica) são 62,84\% e 37,17\% da paisagem, respectivamente. Os elementos de conexão, associados com a proporção de habitats disponível contribuem para o deslocamento da espécie na paisagem (Figura $5)$.

Outro aspecto importante relacionado à utilização dos habitats refere-se ao sucesso de seu uso pelas espécies, o que depende da relação entre a capacidade de deslocamento das espécies (escala de movimentação) e o espaçamento dos habitats (escala de fragmentação) (KIMBERLY e KING, 1999). 
As distâncias entre as manchas de várzeas e das áreas onde há concentração de alimento não difere muito da capacidade de deslocamento da anta na paisagem, não sendo, portanto, um fator limitante à utilização da espécie. Em função disso, e também dos requisitos ecológicos relacionados à extensão de área de vida, pode-se afirmar que a anta possui ampla capacidade perceptual, ou seja, é capaz de perceber habitats ou recursos alimentares preferenciais à distância e que percebam a paisagem em um contexto mais amplo.

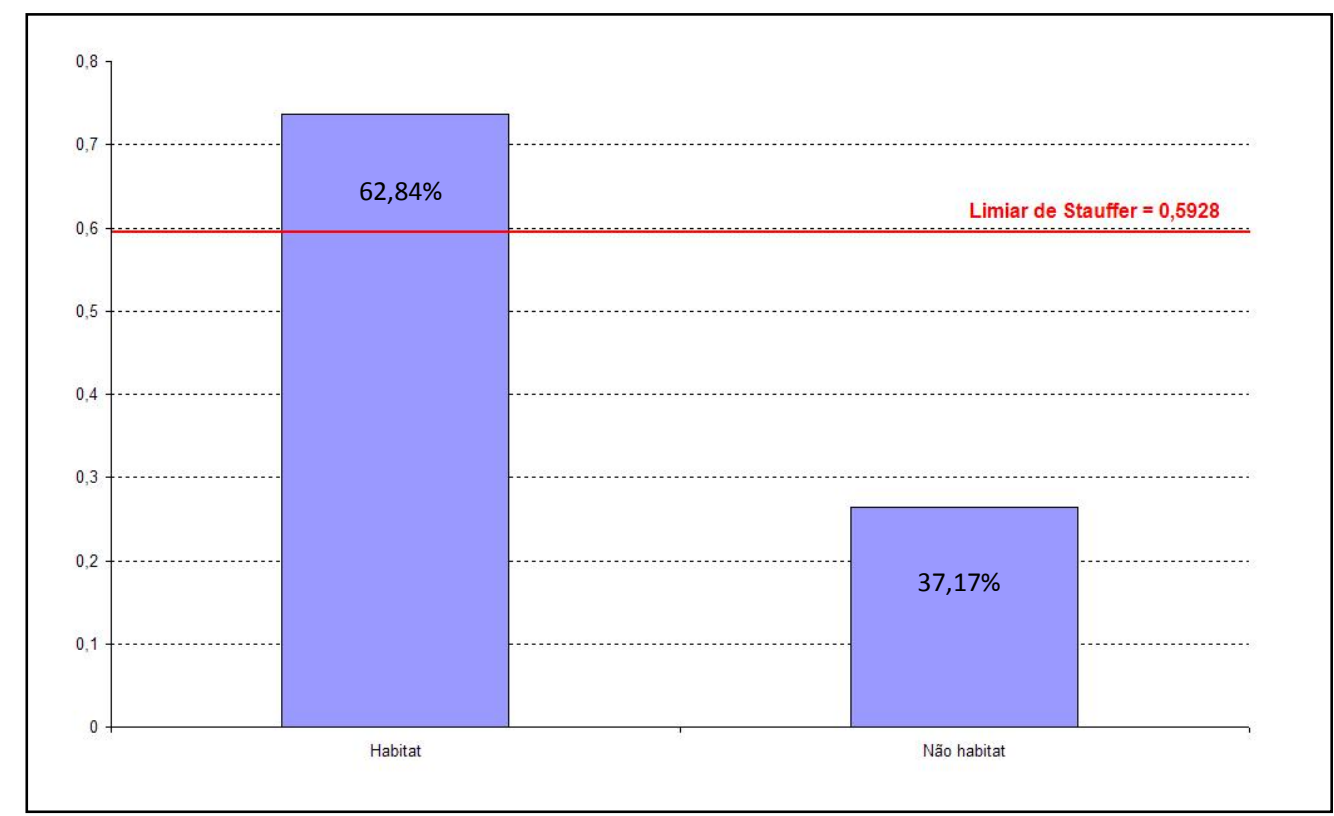

FIGURA 5. Valores da proporção de áreas de habitats e não-habitats na área de uso total do grupo 1 de antas, comparados com o "limiar da percolação de Stauffer".

De maneira geral, embora as condições ambientais de praticamente todas as áreas onde a anta ocorre se encontrem bastante alteradas e empobrecidas floristicamente, as condições paisagísticas (mosaico de ambientes propício à ocorrência e manutenção destes, tipo de matriz que fornece uma continuidade florestal das áreas, permeabilidade/ percolação, que favorecem a conectividade funcional da paisagem, e proporção de elementos de conexão) tornam essas áreas estudadas os principais remanescentes florestais para a manutenção da espécie. Vidolin et al. (2011a) afirmam que estas condições ambientais, alternadas com ambientes florestais nativos contínuos assumem extrema importância para a manutenção da anta. 
Cabe ressaltar, ainda, que os remanescentes florestais estudados, sobretudo aqueles que apresentam mosaico paisagístico constituído por manchas de ambientes úmidos, mesmo que em pequena proporção de área (como por exemplo, a FLG, a Fazenda Santa Gema Geyer, a Fazenda Lageado Grande/ Remasa e a Fazenda Etiene), constituem-se um dos poucos locais no Estado do Paraná onde a espécie ainda pode ser encontrada.

Vidolin et al. (2011b) utilizando métodos de valoração da paisagem, constataram que $61,2 \%$ da FLG possuem ambientes relevantes à conservação das espécies, os quais são constituídos por floresta com predomínio de pinheiro, floresta com predomínio de folhosas, várzeas e alguns trechos de vegetação ciliar do Rio Iratim. Com estes resultados pode-se concluir que a área da Fazenda Lageado Grande apresenta um mosaico de ambientes propício à ocorrência e manutenção de ungulados com a anta (Tapirus terrestris) e o queixada (Tayassu pecari).

\section{Conclusões}

Com os resultados alcançados foi possível obter as seguintes conclusões:

a) As rotas de deslocamento utilizadas pela anta estão associadas aos movimentos para seleção e procura de áreas de alimentos ou para deslocamentos entre habitats-chaves;

b) A anta possui ampla capacidade perceptual, ou seja, é capaz de perceber habitats ou recursos alimentares preferenciais à distância;

c) A espécie é influenciada pela disposição espacial dos seus habitats-chave na paisagem, e não necessariamente pela sua disponibilidade de tamanho de área;

d) De acordo com os índices de paisagem, calculados para a paisagem como um todo, pode-se constatar que a característica da matriz (predominantemente florestal com espécies nativas), associada aos limiares de percolação e à proporção de elementos de conexão existentes, favorece o deslocamento dos animais até as manchas de seus habitats-chaves e para áreas onde há concentração de recursos alimentares; 
e) A anta utiliza rotas de deslocamento estáveis que são sempre utilizadas para trânsito entre a FLG e as áreas do entorno. Estas rotas, em especial aquelas cujo trajeto abrange ambientes ciliares, são indicadores de micro-corredores de biodiversidade;

f) A FLG, juntamente com as Fazendas Santa Gema Geyer, Etiene, Lageado Grande/ Remasa e Faxinal dos Santos, constituem-se uns dos poucos locais no Estado do Paraná onde a anta ainda pode ser encontrada e, por este motivo, medidas de conservação como a criação de RPPNs ou a inserção destas propriedades em programas de incentivo florestal, devem ser direcionadas a estas fazendas.

\section{Referências}

ANDRÉN, $H$. Effects of habitat fragmentation on birds and mammals in landscapes with different proportions of suitable habitat: a review. Oikos, v. 71, p. 355-366, 1994.

BODMER, R. E.; BROOKS, D. M. Diagnóstico e Plano de ação para a anta comum (Tapirus terrestris). In: Tapirs - Status Survey and Conservation Action Plan. IUCN/SSC Tapir Specialist Group, p 126-133. 1997.

CAMPOS, Z. A paisagem na visão dos animais. ADM: Artigo de Divulgação na Mídia, Embrapa Pantanal, v. 68, n.1-3, 2004.

DANIELSON, B. J. Habitat selection, interspecific interactions and landscape composition. Evolutionary Ecology, v. 6, p. 399-411, 1992.

DUNNING, J. B. Ecological processes that affect populations in complex landscapes. Oikos, v. 68, n. 3, p. 169-175, 1992.

EISENBERG, J. F. Introdução. In: Tapirs - status survey and conservation action plan. IUCN/SSC Tapir Specialist Group, 1997. p. 123 - 125.

EMMONS, L. H. Neotropical rainforest mammals: a field guide. University of Chicago Press. Chicago. 1990.

FORERO-MEDINA, G.; VIEIRA, M. V. Conectividade funcional e a importância da interação organismo-paisagem. Oecol. Bras., v.11, n. 4, p. 493-502, 2007.

FORMAN, R. T. T.; GODRON, M. Landscape ecology. USA: J. Wiley, 1986. 
GOMES, P. A. F. F. T. Ocupação e Utilização do espaço pelo Geneta. Tese de Doutorado em Zoologia, Braga: Universidade do Minho, 1998. 110 p.

IMS, R. A. Movement patterns related to special structure. In: HANSSON, L.; FAHRIG, L.; MERRIAN, G. Mosaic landscapes and ecological processes. London: Chapman Y Hall, p. 85-109. 1995.

INTERNATIONAL UNION FOR CONSERVATION OF NATURE AND NATURAL RESOURCES. (IUCN). Red list of threatened species. Disponível em: $<$ http://www.redlist.org>. Acesso em: 15/02/2007.

INTERNATIONAL UNION FOR CONSERVATION OF NATURE AND NATURAL RESOURCES. (IUCN). Red list of threatened species: a global species assessment. Disponível em: <www.iucnredlist.org>. Acesso em: 15/08/2008.

KIMBERLY, A. W.; KING, A. W. Extinction Thresholds for species in Fractal Landscapes. Conservation Biology, v. 13, n. 2, p. 314-326, 1999.

LIEBSCH, D.; MIKICH, S. B. Fenologia reprodutiva de espécies vegetais da Floresta Ombrófila Mista do Paraná, Brasil. Revista Brasil. Bot., v. 32, n. 2, p. 375-391, 2009.

LIEBSCH, D.; MIKICH, S. B.; POSSETTE, R. F. da S.; RIBAS, O. dos S.

Levantamento florístico e síndromes de dispersão em remanescentes de Floresta Ombrófila Mista na região centro-sul do estado do Paraná. Hoehnea, v. 36, n. 2, p. 233-248. 2009.

MARENZI, R. C. Ecologia da paisagem da morraria da Praia Vermelha (SC): subsídio à conservação da biodiversidade de uma área costeira. $204 \mathrm{f}$. Tese (Doutorado em Ciências Florestais) - Setor de Ciências Agrárias, Universidade Federal do Paraná, Curitiba, 2004.

MAY, R. M. The search for patterns in the balance of nature: advances and retreats. Ecology, v. 67, n. 5, p. 1115-1126, 1986.

METZGER, J, P. 2001. O que é ecologia da paisagem? Biota Neotropica 1(1 e 2), BN00101122001. Disponível em http <//www.biotaneotropica.org.br>. Acesso em $12 / 2004$.

METZGER, J. P. Estrutura da Paisagem e Fragmentação: análise bibliográfica. An. Acad. Bras. Ci., v. 71, n. 3, p. 445-463, 1999.

MIKICH, S. B.; BÉRNILS, R. S. Livro vermelho da fauna ameaçada no Estado do Paraná. Curitiba: Instituto Ambiental do Paraná, 2004.

MONTENEGRO, O. L. Aspectos del comportamiento del Tapir (Tapirus terrestris) em la Amazonia Peruana. Res. In: CONGRESSO INTERNACIONAL SOBRE MANEJO 
DE FAUNA SILVESTRE EN LA AMAZONIA, III, 1997, Santa Cruz de la Sierra, Bolívia. Anais... Santa Cruz de la Sierra, 1997. p. 35.

MORAIS, A. A. de; NOVELLE, S. M. H.; SILVA, J. V. C.; GIANGARELLI, D. C.; MONTEIRO, G. T. Padrões de deslocamento de Tapirus terrestrris (Linnaeus, 1758) entre a área do Parque Estadual Mata dos Godoy - PR e fragmentos adjacentes. In: CONGRESSO DE ECOLOGIA DO BRASIL. Fortaleza, VI. Anais... Fortaleza, 2003. p. 405.

NOSS, A.J.; CUÉLLAR, R.L.; BARRIENTOS, J.; MAFFEI, L.; CUÉLLAR, E.; ARISPE, R.; RÚMIZ, D.; RIVERO, K. A camera trapping and radio telemetry study of lowland tapir (Tapirus terrestris) in Bolivian dry forests. Tapir Conservation 12: 24-32. O'BRIEN T.G., KINNAIRD M.F. \& WIBISONO H.T. 2003.

PADILHA, M.; DOWLER, R. C. Tapirus terrestris. Mammalian species, n. 481, p. 18, 1994.

PARANÁ. Avaliação Ecológica Rápida do Corredor Araucária. Instituto Ambiental do Paraná/ Programa Paraná Biodiversidade. 2006.

RICHARD, E.; JULIÁ, P. J.Aspectos generales de la biología, estatus, uso y manejo del Tapir (Tapirus terrestris) en Argentina. REHM, Serie Apuntes, n.1 Versión 2.1, 2000.

SOUTHWOOD, T.R.E. Habitat, the templet for ecological strategies? Journal of animal ecology, v. 46, p. 337-65, 1977.

STAUFFER, D. Introduction to percolation theory. London: Taylor e Francis. 1985.

TAYLOR, P. D.; FAHRIG, L.; HENEIN, K.; MERRIAM, G. Connectivity is a vital element of landscape structure. Oikos, v. 68, p. 571-573, 1993.

TOBLER, M. W. 2006. Ecología de Tapirus terrestris en la selva de Madre de Dios, Perú: Datos preliminarios de un estudio con collares de GPS. In: CONGRESSO INTERNACIONAL SOBRE MANEJO DE FAUNA SILVESTRE NA AMAZÔNIA E AMÉRICA LATINA, VII, 2006, Ilhéus,. Anais... Ilhéus, 2006.

VIDOLIN, G. P. Análise da estrutura da paisagem como subsídio para o planejamento estratégico de conservação da anta (Tapirus terrestris Linnaeus, 1758) e do queixada (Tayassu pecari Link, 1795) em remanescentes da Floresta com Araucária. Tese de Doutorado em Conservação da Natureza. Curitiba: Universidade Federal do Paraná, 2008. 136p.

VIDOLIN, G. P.; BIONDI, D.; WANDEMBRUCK, A. Seletividade de habitats pela anta (Tapirus terrestris) e pelo queixada (Tayassu pecarı) na Floresta com Araucária. Sci. For., v. 37, n. 84, p. 447-458, 2009. 
VIDOLIN, G. P.; BIONDI, D.; WANDEMBRUCK, A. A anta (Tapirus terrestris) em fragmentos de floresta com Araucária, Paraná, Brasil. Floresta, v. 41, n. 4, p. 685694, 2011a.

VIDOLIN, G. P.; BIONDI, D.; WANDEMBRUCK, A. Valoração da paisagem com base nos requisitos ecológicos de Tayassu pecari E DE Tapirus terrestris - Floresta com Araucária, Paraná, Brasil. Ciência Florestal, v. 21, n. 3, p. 509-519, 2011 b.

WITH, K. A.; GARDNER, R. H.; TURNER, M. G. Landscape connectivity and population distributions in heterogeneous environments. Oikos, v. 78, p. 151-169, 1997.

ZOLLNER, P. A. Comparing the landscape level perceptual abilities of forest sciurids in fragmented agricultural landscapes. Landscape Ecology, v. 15, p. 523-533, 2000.

ZOLLNER, P. A.; LIMA, S. L. Illumination and the perception of remote habitat patches by white-footed mice. Animal Behaviour, v. 58, p. 489-500, 1999. 